\title{
Aplicação de Óleo Fúsel Isolado e em Mistura com Glifosato na Pós-Emergência Tardia de Plantas Daninhas ${ }^{1}$
}

\author{
Fusel Oil as Herbicide at Late Weed Postemergence
}

\author{
AZANIA, A.A.P.M. ${ }^{2}$, AZANIA, C.A.M. ${ }^{3}$, MARQUES, M.O. ${ }^{4}$, PAVANI, M.C.M.D. ${ }^{5}$, FURTADO, D.E. ${ }^{6}$ \\ e RODRIGUES, D. ${ }^{7}$
}

\begin{abstract}
RESUMO - Este trabalho foi realizado no Centro de Cana IAC, Ribeirão Preto, com o objetivo de avaliar a eficácia do óleo fúsel isolado e em mistura com glifosato, aplicado na pósemergência tardia de plantas daninhas de uma comunidade natural. O delineamento experimental foi em blocos casualizados (DBC), com 13 tratamentos em quatro repetições, sendo 52 parcelas de $3 \times 3 \mathrm{~m}$ cada. A aplicação dos tratamentos foi realizada em 22/3/ 2006, com equipamento costal pressurizado munido de barra com quatro pontas de pulverização Teejet $110.02 \mathrm{TT}$, regulado para volume de calda de $212 \mathrm{~L} \mathrm{ha}^{-1}$. Avaliaram-se a porcentagem de controle aos 14, 21, 28, 35 e 42 dias após a aplicação do tratamento (DAA) e a massa seca, aos 42 DAA. Para a maioria dos tratamentos somente não houve $100 \%$ de controle devido à presença de plantas daninhas dos gêneros Commelina e Cyperus spp., que, mesmo com partes amareladas, foram mais tolerantes à aplicação dos produtos. O controle obtido com óleo fúsel aplicado isoladamente não ultrapassou 20\%, aos 42 DAA.
\end{abstract}

Palavras-chave: subproduto, controle, herbicida

ABSTRACT - This work was carried out at the Sugarcane Center (Centro de Cana IAC), Ribeirão Preto-SP, to evaluate the effectiveness of fusel oil alone and mixed with glyphosate applied at late weed post-emergence of a natural community. The experimental design was randomized blocks, with 13 treatments and 4 repetitions, totaling 52 plots $3 \times 3 m$ each. Application of the treatments was accomplished on 03/22/2006, with pressurized back sprayer. The control percentages were evaluated at 14,21, 28, 35 and 42 days after treatment (DAA) and weed dry matter was obtained by using a square $0.5 \times 0.5 \mathrm{~m}$ sorted two times on the plots at $42 \mathrm{DAA}$. The less satisfactory results under the control at the end of the experiment were when fusel oil was applied alone. The lack of $100 \%$ control in the main treatments evaluated was due to the presence of the weeds Commelina and Cyperus spp., which were more tolerant to herbicide application. The control efficiency obtained by using fusel oil was no more than $20 \%$ at 42 DAA.

Keywords: by-product, control, herbicide.

\section{INTRODUÇÃO}

Um dos principais problemas enfrentados pela cultura da cana-de-açúcar é a interferência sofrida pela presença das plantas daninhas, que podem provocar perdas na produtividade da cultura de até $85 \%$ quando não controladas adequadamente, segundo Victória Filho \& Christoffoleti (2004). A cana-de-açúcar, apesar de apresentar ciclo $\mathrm{C} 4$ e usar de maneira altamente eficiente os recursos disponiveis para seu crescimento, é afetada nas fases iniciais de crescimento pelas plantas daninhas, principalmente por gramíneas e ciperáceas.

1 Recebido para publicação em 9.3.2007 e na forma revisada em 3.1.2008

Parte da tese do primeiro autor apresentada à FCAVJ/UNESP.

2 Bióloga, doutoranda em Produção Vegetal, FCAVJ/UNESP, bolsista do CNPq, Via de Acesso Prof. Paulo Donato Castellane, km 5, s/n, Jaboticabal-SP, 14870-000, <andrea.azania@hotmail.com>; ${ }^{3}$ Engo-Agro , Dr., Pesquisador Científico, Centro de Cana IAC, Ribeirão Preto-SP; ${ }^{4}$ Prof., Dr., Dep. de Tecnologia, FCAVJ/UNESP, Jaboticabal-SP, 5 Prof. Assistente, Dr., Dep. de Biologia Aplicada à Agropecuária, FCAV/Unesp, Jaboticabal-SP, ${ }^{6}$ Engâ-Agra ${ }^{2}$, estagiária de Matologia, Centro de Cana IAC, Ribeirão PretoSP, ${ }^{7}$ Técnico de apoio, Centro de Cana IAC, Ribeirão Preto-SP. 
Recentemente, foi mencionado um possível potencial dessecante do óleo fúsel sobre plantas daninhas e cana-de-açúcar por Azania (2003). O óleo fúsel é formado da transformação de aminoácidos pelas leveduras durante a fermentação alcoólica, em destilarias, e seus componentes são conhecidos como alcoóis superiores (Botelho, 1945). Em sua composição podem ser encontrados alcoóis etílico, amílico, isoamílico, propílico, butílico, etc. Segundo Almazan et al. (1998), o álcool amílico, isoamílico n-butanol e outros compostos do óleo fúsel podem ser separados através de um processo de destilação, mostrando algumas vantagens econômicas. Entretanto, este outro processo de destilação não é realizado pelas usinas, e sim pelas empresas que compram o produto para comercializá-1o.

Devido ao não-aproveitamento do óleo fúsel pelas usinas, foi iniciado um trabalho envolvendo o seu uso na agricultura, evidenciando potencial para uso do produto. Este subproduto, em todas as concentrações testadas $(100,50$, 25 e 12,5 v/v), inibiu a emergência de plântulas de Sida rhombifolia e Brachiaria decumbens, além de ter dessecado plantas de cana-de-açúcar (Azania et al., 2004). Além disso, constatouse redução na viabilidade de sementes de Sida rhombifolia, principalmente nas maiores concentrações em que o produto foi aplicado. Por outro lado, nas sementes de Brachiaria decumbens houve inviabilização completa em todas as concentrações testadas (Azania et al., 2003).

Contudo, percebeu-se que esse potencial é menor quando se usa o produto em menores concentrações ou quando este é utilizado isoladamente. Diante dessas considerações, este trabalho objetivou avaliar a eficiência do óleo fúsel aplicado isoladamente ou em mistura com herbicida dessecante, em pós-emergência tardia, em uma comunidade natural de plantas daninhas.

\section{MATERIAL E MÉTODOS}

O experimento foi instalado na Fazenda Experimental do Centro de Cana - IAC, sediado em Ribeirão Preto, durante os meses de março a maio de 2006.

No período que precedeu a instalação do experimento, a área experimental consistia de um pomar, que foi removido, sendo o solo, em seguida, gradeado. O solo da área foi classificado como Latossolo Vermelho mesotroférrico (LVmf), e os resultados da sua análise química são apresentados na Tabela 1. Não há registros da aplicação de herbicidas nessa área pelo menos nos últimos dez anos. Após a operação de gradagem, esperou-se que as plantas daninhas germinassem e atingissem estádio de pós-emergência tardia, para aplicação dos tratamentos.

A época de instalação do experimento coincidiu com o final do período das chuvas, quando se registraram temperaturas altas (Tabela 2).

As principais infestantes encontradas na área antes da aplicação dos tratamentos e as respectivas porcentagens de cobertura foram: caruru (Amaranthus spp.) - 3\%, mamona (Ricinus communis) - 8\%, picão-branco (Galinsoga parviflora) - 1\%, carrapicho-de-carneiro (Acanthospermum hispidum) - 1\%, losnabranca (Parthenium histerophorus) - 1\%, papoula-do-méxico (Argemone mexicana) - 1\%, capim pé-de-galinha (Eleusine indica) - 15\%, capimcarrapicho (Cenchrus echinatus) - 1\%, capimcolchão (Digitaria sp) - 15\%, capim-colonião (Panicum maximum) - 9\%, com predominância de trapoeraba (Commelina benghalensis) $-25 \%$ e tiririca (Cyperus sp.) - 20\%.

O delineamento experimental utilizado foi o de blocos casualizados (DBC), com 13 tratamentos em quatro repetições, totalizando 52 parcelas. Cada parcela media $3 \times 3 \mathrm{~m}$, sendo $4,5 \mathrm{~m}^{2}$ de área útil, onde foram aplicados os tratamentos. Entre as parcelas foi deixado espaço de $1 \mathrm{~m}$ de caminho, para não ser necessário entrar nelas durante as avaliações e evitar problemas com deriva no momento da aplicação.

Os tratamentos constaram da utilização de óleo fúsel e da mistura deste com glifosato (Tabela 3). Para determinação dos tratamentos, o critério adotado foi a dose comercialmente aplicada do glifosato e o custo dos produtos, sendo o glifosato cotado em $\mathrm{R} \$ 15,00$ e o óleo fúsel a R\$ 0,40 L, no ano de 2005.

O glifosato foi utilizado na forma de concentrado solúvel (360 $\left.\mathrm{g} \mathrm{L}^{-1}\right)$. O óleo fúsel foi coletado em destilaria e submetido à análise por cromatografia gasosa, sendo encontrados os seguintes alcoóis: i-amílico $(61,60 \%)$; etanol 
Tabela 1 - Atributos químicos do solo da área experimental ${ }^{1}{ }^{\prime}$

\begin{tabular}{|c|c|c|c|c|c|c|c|c|c|c|}
\hline \multicolumn{11}{|c|}{ Análise química } \\
\hline \multirow{2}{*}{$\begin{array}{c}\mathrm{pH} \\
\left(\mathrm{CaCl}_{2}\right)\end{array}$} & \multirow{2}{*}{$\begin{array}{c}\mathrm{MO} \\
\left(\mathrm{g} \mathrm{dm}^{-3}\right)\end{array}$} & \multirow{2}{*}{$\begin{array}{c}P \\
\text { Resina } \\
\left(\mathrm{mg} \mathrm{m}^{-3}\right)\end{array}$} & $\mathrm{K}$ & $\mathrm{Ca}$ & $\mathrm{Mg}$ & $\mathrm{Al}$ & $\mathrm{H}+\mathrm{Al}$ & SB & CTC & \multirow{2}{*}{$\begin{array}{l}\mathrm{V} \\
(\%)\end{array}$} \\
\hline & & & \multicolumn{7}{|c|}{ 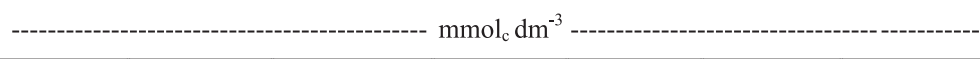 } & \\
\hline 5,0 & 27 & 54 & 3,7 & 43 & 12 & 0 & 45 & 58,7 & 103,7 & 56,6 \\
\hline
\end{tabular}

1/ Análise realizada no DMLab (Dinardo Miranda Laboratório de Análises Agrícolas).

Tabela 2 - Precipitação pluviométrica e temperaturas registradas, durante os meses de março a maio de 2006, na área experimental

\begin{tabular}{|l|c|c|c|}
\hline \multirow{2}{*}{ Mês } & \multirow{2}{*}{$\begin{array}{c}\text { Precipitação } \\
(\mathrm{mm})\end{array}$} & \multicolumn{2}{|c|}{ Temperatura $\left({ }^{\circ} \mathrm{C}\right)$} \\
\cline { 3 - 4 } & 151,1 & Máxima & Mínima \\
\hline Março & 14,6 & 30,3 & 20,2 \\
\hline Abril & 2,0 & 28,9 & 17,2 \\
\hline Maio & 27,0 & 12,7 \\
\hline
\end{tabular}

Fonte: Estação Climatológica da Fazenda Experimental do Centro de Cana - IAC, Ribeirão Preto, SP.

Tabela 3 - Combinação de doses de glifosato e óleo fúsel, compondo os tratamentos testados

\begin{tabular}{|c|c|c|c|}
\hline Tratamento & $\begin{array}{c}\text { Glifosato (L } \\
\left.\mathrm{ha}^{-1}\right)\end{array}$ & $\begin{array}{c}\text { Óleo fúsel (L } \\
\left.\mathrm{ha}^{-1}\right)\end{array}$ & Custo (R\$)/ha \\
\hline 1 & 4,00 & 0 & 60,00 \\
\hline 2 & 0,00 & 150 & 60,00 \\
\hline 3 & 2,50 & 6,25 & 40,00 \\
\hline 4 & 2,00 & 25,00 & 40,00 \\
\hline 5 & 1,50 & 43,75 & 40,00 \\
\hline 6 & 1,00 & 62,50 & 40,00 \\
\hline 7 & 0,00 & 100 & 40,00 \\
\hline 8 & 1,50 & 18,75 & 30,00 \\
\hline 9 & 1,00 & 37,50 & 30,00 \\
\hline 10 & 0,00 & 75,00 & 30,00 \\
\hline 11 & 1,00 & 12,50 & 20,00 \\
\hline 12 & 0,00 & 50,00 & 20,00 \\
\hline 13 & \multicolumn{3}{|c}{ Sem aplicação } \\
\hline
\end{tabular}

(14,46\%); i-butanol (10,30\%); n-propanol (1,69\%); n-butanol (0,67\%); e n-amilico (0,49\%).

A aplicação dos tratamentos, em pós-emergência tardia das plantas daninhas, foi realizada em 22/3/2006, com início às 10 h30 e término às $11 \mathrm{~h} 14$. No momento da aplicação a temperatura ambiente era de $30^{\circ} \mathrm{C}$, com $60 \%$ de umidade relativa do ar, céu com nebulosidade parcial e ventos ausentes. Foi utilizado equipamento costal pressurizado $\left(\mathrm{CO}_{2}\right)$, munido de barra com quatro pontas de pulverização Teejet 110.02 TT VP, regulado para volume de calda de $212 \mathrm{~L} \mathrm{ha}^{-1}$.

Em todos os tratamentos que envolveram óleo fúsel foi adicionado detergente neutro
$(0,2 \% \mathrm{v} / \mathrm{v})$ na calda, para facilitar a mistura do produto com a água.

\section{Variáveis avaliadas}

- Porcentagem de controle: aos 14, 21, 28, 35 e 42 dias após a aplicação do tratamento (DAA). Os valores de porcentagem de controle foram determinados por escala padronizada, para avaliação dos efeitos visuais dos herbicidas sobre plantas daninhas (Rolim, 1989), de acordo com a Tabela 4.

Tabela 4 - Escala de notas para avaliação da porcentagem de controle de plantas daninhas

\begin{tabular}{|c|c|}
\hline$\%$ de controle & Avaliação \\
\hline $99,1-100,0$ & Excelente (E) \\
\hline $96,6-99,0$ & Muito bom (MB) \\
\hline $92,6-96,5$ & Bom (B) \\
\hline $85,1-92,5$ & Suficiente (S) \\
\hline $75,1-85,0$ & Duvidoso (D) \\
\hline $60,1-75,0$ & Insuficiente (I) \\
\hline $40,1-60,0$ & Mau (M) \\
\hline $15,1-40,0$ & Péssimo (P) \\
\hline $0,00-15,0$ & Sem efeito (SE) \\
\hline
\end{tabular}

Fonte: Rolim (1989).

- Biomassa seca: aos 42 DAA, em cada parcela foi lançado, duas vezes, um quadrado amostral de $0,50 \times 0,50 \mathrm{~m}$, estabelecendo uma área de $0,25 \mathrm{~m}^{2}$, em que foram coletadas as plantas presentes. Estas foram colocadas em sacos de papel. O material resultante dessa coleta foi seco em estufa de renovação e circulação forçada de ar e mantido à temperatura aproximada de $60^{\circ}$, até que fosse atingido o peso constante.

A análise estatística dos resultados foi realizada através da análise de variância (teste F). A comparação de médias de tratamentos foi feita empregando-se o teste de Tukey a $5 \%$ de probabilidade. 


\section{RESULTADOS E DISCUSSÃO}

$\mathrm{Na}$ avaliação inicial, realizada aos 14 DAA, a porcentagem de controle visual das plantas daninhas (Tabela 5) foi maior para o tratamento $11\left(1 \mathrm{~L} \mathrm{ha}^{-1}\right.$ glifosato $+12,50 \mathrm{~L} \mathrm{ha}^{-1}$ de óleo fúsel), ou seja, a menor dose do glifosato misturada com a segunda menor dose do óleo fúsel, seguida do tratamento em que foi aplicado apenas glifosato $\left(4 \mathrm{~L} \mathrm{ha}^{-1}\right)$. O glifosato tem como característica, segundo Lacerda (2003), a lenta evolução de seus sintomas de ação. Os tratamentos 7 (100 $\mathrm{L} \mathrm{ha}^{-1}$ de óleo fúsel), 12 (50 L ha ${ }^{-1}$ de óleo fúsel), 2 (150 $\mathrm{L} \mathrm{ha}^{-1}$ de óleo fúsel) e 10 (75 L ha' ${ }^{-1}$ de óleo fúsel) não diferiram entre si e apresentaram os piores resultados de controle, aos 14 DAA. Esses tratamentos constaram da aplicação de óleo fúsel sem qualquer mistura com glifosato.

Aos 21 DAA, praticamente todos os tratamentos tiveram aumento da porcentagem de controle das plantas daninhas, com exceção dos tratamentos $9\left(1 \mathrm{~L} \mathrm{ha}^{-1}\right.$ de glifosato + $37,50 \mathrm{~L} \mathrm{ha}^{1}$ de óleo fúsel) e $11\left(1 \mathrm{~L} \mathrm{ha}^{-1} \mathrm{de}\right.$ glifosato $+12,50 \mathrm{~L} \mathrm{ha}^{-1}$ de óleo fúsel), nos quais esta porcentagem diminuiu, e o tratamento 7 (100 L ha ${ }^{-1}$ de óleo fúsel), em que o controle foi de $0 \%$ em todas as avaliações. No tratamento em que se aplicou apenas glifosato (tratamen- to $1-4 \mathrm{~L} \mathrm{ha}^{-1}$ ), a eficiência de controle foi de $90 \%$, superior aos valores obtidos com a aplicação de óleo fúsel isolado. Os resultados de controle com glifosato corroboram a informação de Rodrigues \& Almeida (2005), de que o herbicida pode demorar de 4 a 20 dias até a necrose e morte, conforme a espécie de planta.

Exceto os tratamentos 7 (100 L ha-1 de óleo fúsel) e 12 (50 L ha-1 de óleo fúsel), aos $28 \mathrm{DAA}$, todos os outros resultaram em aumento na porcentagem de controle. O glifosato (tratamento 1) apresentou $95 \%$ de controle, seguido dos tratamentos $5\left(1,50 \mathrm{~L} \mathrm{ha}^{-1}\right.$ de glifosato + 43,75 $\mathrm{L} \mathrm{ha}^{-1}$ de óleo fúsel), 8 (1,50 $\mathrm{L} \mathrm{ha}^{-1}$ de glifosato + 18,75 $\mathrm{L} \mathrm{ha}^{-1}$ de óleo fúsel) e 11 ( $1 \mathrm{~L} \mathrm{ha}^{-1}$ de glifosato $+12,50 \mathrm{~L} \mathrm{ha}^{-1}$ de óleo fúsel), com $80 \%$ de controle. Para essa avaliação, a mistura dos dois produtos apresentou resultados interessantes, especialmente por não serem resultados finais. No entanto, resultados finais cujo percentual de controle estejam na casa dos $80 \%$ são classificados como duvidosos (Rolim, 1989).

Aos 35 DAA, o glifosato isolado havia dessecado completamente as plantas daninhas (tratamento 1), seguido por $87,5 \%$ de controle para os tratamentos $5\left(1,50 \mathrm{~L} \mathrm{ha}^{-1}\right.$ de glifosato + 43,75 L ha ${ }^{-1}$ de óleo fúsel) e 8 (1,50 L ha-1 de

Tabela 5 - Porcentagem de controle das plantas daninhas aos 14, 21, 28, 35 e 42 DAA (dados médios de quatro repetições)

\begin{tabular}{|c|c|c|c|c|c|c|c|c|c|c|c|c|}
\hline \multirow{2}{*}{\multicolumn{3}{|c|}{ Tratamento }} & \multicolumn{10}{|c|}{ Porcentagem de controle } \\
\hline & & & \multicolumn{2}{|c|}{14 DAA } & \multicolumn{2}{|c|}{$21 \mathrm{DAA}$} & \multicolumn{2}{|c|}{$28 \mathrm{DAA}$} & \multicolumn{2}{|c|}{$35 \mathrm{DAA}$} & \multicolumn{2}{|c|}{42 DAA } \\
\hline & $\begin{array}{c}\text { Glifosato } \\
\left(\mathrm{L} \mathrm{ha}^{-1}\right)\end{array}$ & $\begin{array}{l}\text { Óleo fúsel } \\
\left(\mathrm{L} \mathrm{ha}^{-1}\right)\end{array}$ & Orig. & Transf. & Orig & Transf. & Orig. & Transf. & Orig. & Transf. & Orig. & Transf. \\
\hline 1 & 4,00 & 0 & 77,5 & $63,92 \mathrm{a}$ & 90 & $74,47 \mathrm{a}$ & 95 & $81,02 \mathrm{a}$ & 100 & $90,0 \mathrm{a}$ & 100 & $90,0 \mathrm{a}$ \\
\hline 2 & 0,00 & 150 & 2,5 & $7,77 \mathrm{~cd}$ & 5,0 & $9,77 \mathrm{~cd}$ & 12,5 & $14,36 \mathrm{~cd}$ & 12,5 & $14,36 \mathrm{~cd}$ & 5,0 & $9,77 \mathrm{~cd}$ \\
\hline 3 & 2,50 & 6,25 & 52,5 & 44,62 abcd & 57,5 & $47,74 \mathrm{abcd}$ & 67,5 & $57,47 a b c$ & 72,5 & $64,03 a b c$ & 72,5 & $64,03 \mathrm{abc}$ \\
\hline 4 & 2,00 & 25,00 & 47,5 & 41,68 abcd & 52,5 & 44,62 abcd & 62,5 & $51,31 \mathrm{abcd}$ & 72,5 & $64,03 \mathrm{abc}$ & 75,0 & $68,51 \mathrm{ab}$ \\
\hline 5 & 1,50 & 43,75 & 60,0 & $51,99 \mathrm{ab}$ & 75,0 & $60,84 \mathrm{ab}$ & 80 & $67,0 \mathrm{ab}$ & 87,5 & $72,41 \mathrm{ab}$ & 92,5 & $78,96 \mathrm{a}$ \\
\hline 6 & 1,00 & 62,50 & 57,5 & $50,55 \mathrm{abc}$ & 62,5 & $53,43 a b c$ & 65,0 & $55,03 \mathrm{abcd}$ & 67,5 & 56,70 abcd & 70,0 & $61,19 \mathrm{abcd}$ \\
\hline 7 & 0,00 & 100 & 0 & $4,05 \mathrm{~d}$ & 0 & $4,05 \mathrm{~d}$ & 0 & $4,05 \mathrm{~d}$ & 0 & $4,05 \mathrm{~d}$ & 0 & $4,05 \mathrm{~d}$ \\
\hline 8 & 1,50 & 18,75 & 65,0 & $54,97 \mathrm{ab}$ & 72,5 & $59,56 \mathrm{ab}$ & 80 & $67,0 \mathrm{ab}$ & 87,5 & $72,41 \mathrm{ab}$ & 87,5 & $72,41 \mathrm{ab}$ \\
\hline 9 & 1,00 & 37,50 & 65,0 & $54,97 \mathrm{ab}$ & 62,5 & $52,90 \mathrm{abc}$ & 77,5 & $62,51 \mathrm{abc}$ & 80,0 & $64,19 a b c$ & 80,0 & $64,19 a b c$ \\
\hline 10 & 0,00 & 75,00 & 15,0 & $15,81 \mathrm{bcd}$ & 15,0 & $15,81 \mathrm{~cd}$ & 20 & $18,99 \mathrm{bcd}$ & 20,0 & $18,99 \mathrm{bcd}$ & 20,0 & $18,99 \mathrm{bcd}$ \\
\hline 11 & 1,00 & 12,50 & 85,0 & $68,31 \mathrm{a}$ & 77,5 & $62,12 \mathrm{ab}$ & 80 & $64,58 \mathrm{abc}$ & 82,5 & $69,06 \mathrm{abc}$ & 87,5 & $72,80 \mathrm{ab}$ \\
\hline 12 & 0,00 & 50,00 & 0 & $4,05 \mathrm{~d}$ & 20,0 & 18,99 bcd & 20 & $18,99 \mathrm{bcd}$ & 20,0 & 18,99 bcd & 20,0 & 18,99 bcd \\
\hline \multirow[t]{4}{*}{13} & \multicolumn{2}{|c|}{ Sem aplicação } & 0 & $4,05 \mathrm{~d}$ & 0 & $4,05 \mathrm{~d}$ & 0 & $4,05 \mathrm{~d}$ & 0 & $4,05 \mathrm{~d}$ & 0 & $4,05 \mathrm{~d}$ \\
\hline & \multicolumn{2}{|c|}{ Blocos } & & $1,46 \mathrm{~ns}$ & & $1,91 \mathrm{~ns}$ & & $2,24 \mathrm{~ns}$ & & $2,03 \mathrm{~ns}$ & & $1,18 \mathrm{~ns}$ \\
\hline & \multicolumn{2}{|c|}{ Trat. } & & $8,26 * *$ & & $8,15^{* *}$ & & $7,03 * *$ & & $7,52 * *$ & & $7,69 * *$ \\
\hline & \multicolumn{2}{|c|}{ CV (\%) } & & 48,09 & & 44,60 & & 47,08 & & 46,62 & & 47,33 \\
\hline
\end{tabular}

DAA (dias após tratamento). Trans.: dados transformados em $\sqrt{\mathrm{x}+0,5}$; Orig.: dados originais observados. 
glifosato $+18,75 \mathrm{~L} \mathrm{ha}^{-1}$ de óleo fúsel) e $82,5 \%$ para o tratamento $11\left(1 \mathrm{~L} \mathrm{ha}^{-1}\right.$ de glifosato + $12,50 \mathrm{~L} \mathrm{ha}^{-1}$ de óleo fúsel). É importante ressaltar que os tratamentos que aqui apresentaram os melhores resultados são os mesmos que se destacaram na avaliação realizada aos 28 DAA. Os valores dos tratamentos 5 e 8, que aumentaram de uma semana para a outra, fazem com que a avaliação seja considerada suficiente, segundo a escala de Rolim (1989), e excelente para o glifosato.

$\mathrm{Na}$ avaliação final, aos 42 DAA, o glifosato isolado propiciou maior porcentagem de controle, repetindo os resultados encontrados na avaliação da semana anterior. Pela escala de Rolim (1989), o controle exercido pelo glifosato foi excelente e suficiente para os tratamentos 5 , 8 e 11, que consistiam da mistura das menores doses de glifosato com óleo fúsel. É importante salientar que, embora estes tratamentos tenham proporcionado controle pouco inferior ao tratamento com glifosato, os custos com o uso do produto foram reduzidos pouco mais de $50 \%$.

Deve-se ressaltar que os tratamentos 5 (1,50 L ha-1 de glifosato + 43,75 L ha-1 de óleo fúsel), 6 (1 L ha ${ }^{-1}$ de glifosato $+62,50 \mathrm{~L} \mathrm{ha}^{-1}$ de óleo fúsel), 8 (1,50 $\mathrm{L} \mathrm{ha}^{-1}$ de glifosato + $18,75 \mathrm{~L} \mathrm{ha}^{1}$ de óleo fúsel), 9 ( $1 \mathrm{~L} \mathrm{ha}^{-1}$ de glifosato $+37,50 \mathrm{~L} \mathrm{ha}^{-1}$ de óleo fúsel) e 11 ( $1 \mathrm{~L} \mathrm{ha}^{-1}$ de glifosato $+12,50 \mathrm{~L} \mathrm{ha}^{-1}$ de óleo fúsel) somente não receberam $100 \%$ de controle nas avaliações devido às repetições nas quais havia a presença de plantas daninhas dos gêneros Commelina e Cyperus spp., que, mesmo com partes amareladas, foram mais tolerantes à aplicação dos produtos, não sendo dessecadas, enquanto todas as outras espécies foram controladas. As plantas de Commelina benghalensis (trapoeraba) têm sido uma preocupação, segundo Voll et al. (2005), porque mostram dificuldade de controle na dessecação.

Entretanto, o controle de Commelina benghalensis pode ser facilitado no campo, sobretudo quando a aplicação dos herbicidas é realizada no periodo entre abril e maio. É nesse período que as plantas de trapoeraba se apresentam mais suscetiveis aos herbicidas, pois sua população está em declínio e no final de seu ciclo (Penckowski \& Rocha, 2006).

No caso deste trabalho, a aplicação dos produtos foi realizada no final de março, época de maiores precipitações e temperaturas, conforme visto na Tabela 2. Um dia antes da aplicação dos produtos foram registrados $29,8 \mathrm{~mm}$ de precipitação, e uma semana após a aplicação os valores foram de $12,2 \mathrm{~mm}$, o que pode ter aumentado o controle das plantas daninhas em função do aumento do conteúdo de água no solo (Hammerton, 1967).

A população em que foram aplicados os produtos era bem variável, porém havia predominância dos gêneros Commelina e Cyperus spp. Mesmo com infestação alta, houve excelente grau de controle das plantas de trapoeraba, que foram dessecadas no tratamento com glifosato - efeito que não se repetiu quando do emprego do óleo fúsel.

Os resultados menos satisfatórios sob o ponto de vista de controle no final do experimento foram aqueles nos quais o óleo fúsel foi aplicado isoladamente. Verifica-se pela Tabela 4 que o óleo fúsel isolado chegou ao máximo de $20 \%$ de controle no final dos 42 DAA, podendo ser considerado péssimo.

A análise estatística aplicada aos valores de massa seca (Tabela 6) é coerente com os dados da porcentagem de controle, em que se verifica que o glifosato dessecou completamente as plantas.

Tabela 6 - Dados de massa seca determinada após 42 DAA (média de quatro repetições)

\begin{tabular}{|c|c|c|c|}
\hline \multirow{2}{*}{ Tratamento } & Glifosato & Óleo fúsel & Massa seca \\
\cline { 2 - 4 } & ------------ L ha $^{-1}-----------$ & $-------\mathrm{g}$------ \\
\hline 1 & 4,00 & 0 & $0,71 \mathrm{~d}$ \\
\hline 2 & 0,00 & 150 & $12,84 \mathrm{a}$ \\
\hline 3 & 2,50 & 6,25 & $4,25 \mathrm{bcd}$ \\
\hline 4 & 2,00 & 25,00 & $3,39 \mathrm{~cd}$ \\
\hline 5 & 1,50 & 43,75 & $4,21 \mathrm{bcd}$ \\
\hline 6 & 1,00 & 62,50 & $8,13 \mathrm{abc}$ \\
\hline 7 & 0,00 & 100,00 & $11,14 \mathrm{ab}$ \\
\hline 8 & 1,50 & 18,75 & $7,30 \mathrm{abcd}$ \\
\hline 9 & 1,00 & 37,5 & $5,96 \mathrm{abcd}$ \\
\hline 10 & 0,00 & 75,00 & $11,11 \mathrm{ab}$ \\
\hline 11 & 1,00 & 12,50 & $6,02 \mathrm{abcd}$ \\
\hline 12 & 0,00 & 50,00 & $10,55 \mathrm{abc}$ \\
\hline 13 & 0,00 & 0,00 & $12,81 \mathrm{a}$ \\
\hline & & Blocos & $0,20 \mathrm{~ns}$ \\
\cline { 2 - 4 } & & Tratamento & $7,13 * *$ \\
\cline { 2 - 4 } & CV $(\%)$ & 38,50 \\
\hline
\end{tabular}

Dados transformados em $\sqrt{\mathrm{x}+0,5}$.

DAA (dias após tratamento). Trans.: dados transformados em $\sqrt{\mathrm{x}+0,5}$; Orig.: dados originais observados. 
Os maiores valores para massa seca foram encontrados na maior concentração do óleo fúsel, cujos valores se situaram nos mesmos niveis daqueles obtidos com o tratamento testemunha.

Na avaliação da eficiência da aplicação dos produtos através da quantidade de massa seca produzida, pressupõe-se que, quanto menor a massa seca, maior foi o controle. Nesse caso, de acordo com a Tabela 5, depois do glifosato, os melhores resultados (tratamentos) apresentaram-se na seguinte ordem decrescente: 4 (2 $\mathrm{L} \mathrm{ha}^{-1}$ de glifosato $+25 \mathrm{~L} \mathrm{ha}^{-1}$ de óleo fúsel), 5 (1,50 L ha ${ }^{-1}$ de glifosato $+43,75 \mathrm{~L} \mathrm{ha}^{-1}$ de óleo fúsel), 3 (2,50 L ha-1 de glifosato $+6,25 \mathrm{~L} \mathrm{ha}^{-1}$ de óleo fúsel), 9 ( $1 \mathrm{~L} \mathrm{ha}^{-1}$ de glifosato + $37,5 \mathrm{~L} \mathrm{ha}^{-1}$ de óleo fúsel), $11\left(1 \mathrm{~L} \mathrm{ha}^{-1}\right.$ de glifosato $+12,5 \mathrm{~L} \mathrm{ha}^{-1}$ de óleo fúsel) e 6 ( $1 \mathrm{~L} \mathrm{ha}^{-1} \mathrm{de}$ glifosato $+62,5 \mathrm{~L} \mathrm{ha}^{-1}$ de óleo fúsel).

Em razão da falta de controle de plantas daninhas e da maior quantidade de massa seca produzida, pode-se afirmar que o produto, isoladamente, não apresenta possibilidade de uso, nas doses e condição em que foi aplicado, para todas as plantas daninhas presentes no experimento. A mistura do óleo fúsel com glifosato apresentou-se eficaz para todas as espécies presentes da área, exceto Cyperus spp. e Commelina spp., que, apesar de apresentarem partes amareladas e redução de tamanho, não foram completamente controladas.

\section{LITERATURA CITADA}

ALMAZAN, O.; GONZALEZ, L.; GALVEZ, L. The sugarcane, its by-products and co-products. Asociacion de Tecnicos Azucareros de Cuba. Food Agric. Res. Council, Réduit, Mauritius, p. 13-18, 1998.
AZANIA, A. A. P. M. Influência de subprodutos da indústria alcooleira nos atributos químicos do solo e em plantas de cana-de-açúcar, guanxuma e capim-

braquiária. 2003. 81 f. Dissertação (Mestrado em Produção Vegetal) - Universidade Federal de São Paulo, Jaboticabal, 2003

AZANIA, A. A. P. M. et al. Emergência e desenvolvimento de guanxuma (Sida rhombifolia), capim-braquiária (Brachiaria decumbens) e cana-de-açúcar (Saccharum spp.) influenciados por subprodutos da destilação do álcool. Planta Daninha, v. 22, n. 3, p. 331-336, 2004

AZANIA, A. A. P. M. et al. Germinação de sementes de Sida rhombifolia e Brachiaria decumbens influenciada por vinhaça, flegmaça e óleo fúsel. Planta Daninha, v. 21, n. 3, p. $443-449,2003$

BOTELHO, J. Impurezas do álcool etílico. Brasil Açuc., v. 25, p. 99-101, 1945.

HAMMERTON, J. L. Environmental factors and susceptibility to herbicides. Weeds, v. 15, n. 4, p. 330-336, 1967.

LACERDA, A. L. S. Fluxos de emergência e banco de sementes de plantas daninhas em sistema de semeadura direta e convencional e curvas dose-resposta ao glifosato. 2003. $141 \mathrm{f}$. Tese (Doutorado em Fitotecnia) Escola Superior de Agricultura "Luiz de Queiroz", Piracicaba, 2003.

PENCKOWSKI, L. H.; ROCHA, D. C. Guia ilustrado de identificação e controle de espécies de trapoerabas. Castro: Fundação ABC, 2006. 50 p.

RODRIGUES, B. N.; ALMEIDA, F. S. Guia de herbicidas. 5.ed. Londrina: 2005. 592 p.

ROLIM, J. C. Proposta de utilização da escala EWRC modificada em ensaios de campo com herbicidas. Araras: IAA/PLANALSUCAR. Coordenadoria Regional Sul, 1989. 3 p. (Não Publicado)

VICTORIA FILHO, R.; CHRISTOFFOLETI, P. J. Manejo de plantas daninhas e produtividade da cana. Visão Agrícola, n. 1, p. 2-9, 1987

VOLL, E. et al. A dinâmica das plantas daninhas e práticas de manejo. Londrina: Embrapa Soja, 2005. 85 p. 